\section{Gallium (III)-Metalloporphyrin Grafted Magnetite Nanoparticles for Fluoride Removal from Aqueous Solutions}

\author{
Behnoosh Asgari $^{1^{*}}$ and James Bowen ${ }^{2}$ \\ ${ }^{1}$ Islamic Azad University, Central Branch, Tehran, Iran \\ ${ }^{2}$ Department of Engineering and Innovation, The Open University, Walton Hall, Milton Keynes, UK \\ *Corresponding author: Asgari B, Islamic Azad University, Central Branch, Tehran, Iran, Tel: +982147911; E-mail: behnooshasgari@gmail.com
}

Received: June 12, 2017; Accepted: August 04, 2017; Published: August 11, 2017

Copyright: (C) 2017 Asgari B, et al. This is an open-access article distributed under the terms of the Creative Commons Attribution License, which permits unrestricted use, distribution, and reproduction in any medium, provided the original author and source are credited.

\begin{abstract}
Fluoride is a critical micronutrient for human health and is usually ingested through food and drinking water. This technique has done in monitoring the concentration of fluoride in water complications at mining operation that it effects on the environment. $\mathrm{Fe}_{3} \mathrm{O}_{4}$ nanoparticles were synthesized by coprecipitation of $\mathrm{Fe}^{2+}$ and $\mathrm{Fe}^{3+}$ in an alkaline solution, their surface was then modified with 3-aminopropyltriethoxysilane and a $\mathrm{Ga}(\mathrm{III})$ porphyrin complex, $\mathrm{Ga}$ (TCPP) $\mathrm{Cl}_{2}$ [TCPP: tetrakis (4-carboxyphenyl) porphyrin]. The morphology and physical properties of these modified magnetic nanoparticles were examined by X-ray diffraction (XRD), Transmission electron microscopy (TEM), Fourier transform infrared spectroscopy (FT-IR), and thermogravimetric analysis (TGA). The batch experiments showed that the nanoparticles could be used to remove fluoride ions from aqueous solution, achieving an extraction efficiency in excess of $96 \%$ for an initial fluoride concentration of $10 \mathrm{mg} / \mathrm{L}$. This was obtained at $\mathrm{pH} 5.5$ using $50 \mathrm{mg}$ of modified nanoparticles and a contact time of $30 \mathrm{~min}$.
\end{abstract}

Keywords: Fluoride ion; Metalloporphyrin; Magnetite; Nanoparticles; Wastewater treatment; Surface modification

\section{Introduction}

Fluoride in the environment happens through its natural existence on the earth's crust and industrial activities, especially electroplating, glass, steel, aluminum, and enricher industries. The discharge of such wastewater leads to the fluoride contamination of surface and ground water. The contamination of ground water with fluoride can occur naturally by the dissolution of fluoride rich minerals whereas artificial pollution occurs due to the waste water produced from mine, mental refining, plating industries, aluminum smelters and high-tech semiconductor factories [1-5]. Fluoride pollution of the industrial wastewater is one of the significant problems worldwide imposing a severe threat to human health [6]. This method has done in controlling the concentration of fluoride in water problems at mining operation that it effects on the environment. Mine water emanates from working and abandoned surface and underground mines. Usually, it is ground water percolating through the host rocks or sediments, collected by the shafts, galleries, or open pits. Although mine water is not necessarily contaminated, in many cases it contains elevated metal or acidity values which cause a severs threat to the receiving water courses and river catchments. Noncontaminated mine water is used for several purposes, e.g., as cooling water for power plants, drinking water, mineral water, or for agricultural purposes [7]. As an environmental element, fluoride has received much attention due to its both useful and harmful effect on health. For example, while low concentration of fluoride in drinking water can cause dental cavities, excess concentration in drinking water cause dental and skeletal fluorosis, indicating the importance of standardization of this element at a recommended range in drinking water was $1.5 \mathrm{mg} / \mathrm{L}$ by World Health Organization (WHO). In order to reduce the concentration of fluoride in water, various defluoridation technologies have been developed, including: viz., adsorption, ion exchange, precipitation and the membrane process such as reverse osmosis [8], Nano filtration [9], electro dialysis [10] and Donnan dialysis [11]. Adsorption is an efficient and common process in de-fluoridation of water, with satisfactory results and vast applications. Different sorbents have been investigated for removing fluoride, such as: active alumina [12], clay [13], activated carbon [14] and some other sorbents [15]. Recently, many studies have been concentrated on developing novel ionophores with useful specificity for anion [16]. For example, it is found that Gaoctaethyl porphyrin $[\mathrm{OEP}][17,18]$ can be applied as a useful ionophore in producing membrane electrodes with significantly enhanced properties, such as favorable selectivity. In $\mathrm{Ga}(\mathrm{III})$ metallophorphyrin, the main reason for enhanced selectivity of fluoride can be attributed to the strong interaction between fluoride anion and the $\mathrm{Ga}(\mathrm{III})$ cation available in the structure of metalloporphyrin. As building blocks, nanoparticles play an important role in producing nanomaterials, due to their small size, which gives them a high surface area-to-volume ratio, resulting in new magnetic, electrical and optical properties. Improving chemical reactivity is another significant effect of the large surface area of nanoparticles, which provides the possibility for chemical interactions with other chemical species that are available in the environment. There are other abilities for using of nanoparticles such as: adsorption and recovery of some ligands, dyes and ionic species, which are available in the literature [19-24]. The main specification of these nanosorbants, and one which can be considered as their main advantage, is their ability to recover nanoparticles using their external magnetic field. In the mentioned material, dipole/dipole attraction and agglomeration can be created as a basis and a passive layer; this is attributable to important capabilities like high chemical activity, their oxidation ability in air and the loss of magnetism. However, some operations, such as modification of post- synthetic surface are essential [25-31]. For coated metal oxides at the nanoscale, the most common modification method is aminopropyltriethoxysilane (APTES). However, nanomaterials lack 
the target-selective ability, which makes them a weak candidate for samples with complicated matrices. All of this indicates the necessity for functionalization as a tool for inducing selective targeting in nanomaterials [32-40]. For example, Ga-porphyrin is a useful ionophore which can be used in membrane electrodes [41,42]. In other words, it is possible to fabricate a new type of magnetic nanosorbent with high affinity toward fluoride and favorable magnetic reparability by combining the $\mathrm{Ga}(\mathrm{III})$ porphyrin and the magnetic nanoparticle. This paper investigates a new type of nanomagnet which is an APTES coated magnetite, functionalized with the $\mathrm{Ga}$ (III) tetra (4-carboxy phenyl) porphyrin dichloride are represented in Figure 1.

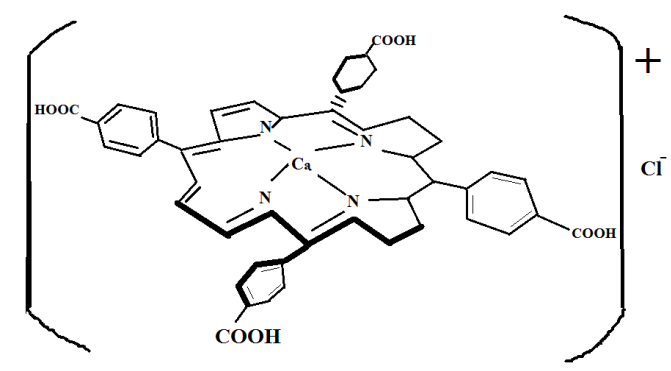

Figure 1: Schematic depiction of the metalloporphyrin used in this work.

\section{Experimental}

\section{Materials}

The most important materials were ferrous chloride tetrahydrate $\left(\mathrm{FeCl}_{2} .4 \mathrm{H}_{2} \mathrm{O}\right)$, dichloromethane (DCM), Ferric chloride hexahydrate $\left(\mathrm{FeCl}_{3} \cdot 6 \mathrm{H}_{2} \mathrm{O}\right)$, APTES, methanol, ethanol, dicyclohexylcarbodiimide (DCHC), 4-paracarboxybenzaldehde, propynoyic acid, pyrrole, N, Ndimethylformamide (DMF), gallium acetate, dimethyl sulfoxide (DMSO), sodium fluoride, sodium salts of indicated anions and deionized water in all experiments were graded analytically. Free basic tetrakis (4-carboxyphenyl) porphyrin (TCPP) (Aldrich) was dried under vacuum at $600 \mathrm{C}$ before using $\mathrm{Ga}(\mathrm{TCPP}) \mathrm{Cl}_{2}$ was prepared using methods described in the literature $[43,44]$.

\section{Equipment}

Morphology of the samples was investigated using TEM with Zeiss 900 and $80 \mathrm{KV}$ voltage. Powder X-ray diffraction (XRD) patterns of the solid produces in the $2 \theta$ range of $5-80^{\circ}$ using a $\mathrm{PW}-1840$ diffractometer were found from Philips Co. [45] with $\mathrm{Cu} \kappa a$ radiation $(\lambda=1.54178 \AA$ ) . Thermogravimetric analysis was performed using a Mettler Toledo TGA/SDTA 851. Samples were heated under a static air atmosphere from ambient to $1000^{\circ} \mathrm{C}$ at a rate of $10^{\circ} \mathrm{C} / \mathrm{min}$. Ion chromatography (IC) determinations were carried out using a S1122 Sykam ion chromatograph. $\mathrm{pH}$ measurements were performed with a Denver Instrument Company $9710.1 \mathrm{pH}$ meter kit UB-5. FT-IR spectra were recorded with a IFS 88 FT-IR spectrophotometer from Bruker Co., using a standard $\mathrm{KBr}$ pellet technique.

\section{Sorbent preparation}

Synthesis of $\mathrm{Fe}_{3} \mathrm{O}_{4}$ nanoparticles: Co-precipitation is known to be one of the best methods for synthesis of $\mathrm{Fe}_{3} \mathrm{O}_{4}$ nanoparticles, based on a study performed by Maity [45,46]. Using this method, $2 \mathrm{~g}$ $\mathrm{FeCl}_{2} .4 \mathrm{H}_{2} \mathrm{O}$ and $5.2 \mathrm{~g} \mathrm{FeCl}_{3} \cdot 6 \mathrm{H}_{2} \mathrm{O}$ were used, with $25 \mathrm{~mL}$ deionized water added. The mixed solution was stirred under $\mathrm{N}_{2}$ at $80^{\circ} \mathrm{C}$ for $1 \mathrm{~h}$. $100 \mathrm{~mL}$ of aqueous $1.5 \mathrm{M} \mathrm{NaOH}$ was then injected into the mixture and stirred under $\mathrm{N}_{2}$ for $1 \mathrm{~h}$. Next, precipitated particles were washed with deionized water three times in order to remove mineral salts; the solution was subsequently washed with ethanol three times to remove organic materials. In the next step precipitated particles were separated with magnets, and finally $\mathrm{Fe}_{3} \mathrm{O}_{4}$ nanoparticles were dried in an oven at $50^{\circ} \mathrm{C}$ for $24 \mathrm{~h}$.

Modification of $\mathrm{Fe}_{3} \mathrm{O}_{4}$ nanoparticles with APTES group: $\mathrm{Fe}_{3} \mathrm{O}_{4} /$ APTES nanoparticles were synthesized according to a previously described method $[47,48]$. This reaction was between APTES and a hydroxyl group on the surface of the magnetite available in the alkaline solution; the bond Fe-O-H changed with Fe-O-Si [49]. 2.3 g magnetic nanoparticles, were dispersed in $100 \mathrm{~mL}$ ethanol using a sonication method, for about $1 \mathrm{~h}$; under continuous mechanical stirring, 20.34 $\mathrm{mL}$ APTES was added. This reaction was achieved for $20 \mathrm{~h}$ under $\mathrm{N}_{2}$ atmosphere. The $\mathrm{Fe}_{3} \mathrm{O}_{4}$ /APTES nanoparticles were prepared and separated with a magnet, and were washed with ethanol and deionized water three times. Finally, $\mathrm{Fe}_{3} \mathrm{O}_{4}$ /APTES nanoparticles were dried under vacuum at $70^{\circ} \mathrm{C}$.

Grafting of $\mathrm{Ga}$ (TCPP) group at the surface of $\mathrm{Fe}_{3} \mathrm{O}_{4}$ /APTES: The metalloporphyrin structure is designed to accept different ions, based on central metal and complex formation; the metalloporphyrin is used instead of pulling electron groups, which gathers them on nonminerals support, making them a good choice for separation and specific to ions [50]. $10 \mathrm{~g}$ paracarboxide benzaldehyde and $5 \mathrm{~mL}$ pyrrole, mixed in the bottom flask, were stirred under $\mathrm{N}_{2}$, followed by the addition of $250 \mathrm{~mL}$ propionic acid. The mixture was refluxed at $140^{\circ} \mathrm{C}$ for $30 \mathrm{~min}$. The product was filtered with filter papers that does not have disturbance in this reaction and this reaction has done under vacuum then allowed to cool to room temperature, washed with methanol, and then washed with deionized water at $70-80^{\circ} \mathrm{C}$. Finally, the product was dried under vacuum to absorb the acid from the substance. Increasing time of reaction does not have effect on reaction efficiency only purity of product get decreased. $2 \mathrm{~g} \mathrm{H}_{2}$ (TCPP) poured into balloon was stirred under $\mathrm{N}_{2}$. After adding $25 \mathrm{~mL} \mathrm{DMSO}$ and 4.3 g Ga(III), acetate $4 \mathrm{H}_{2} \mathrm{O}$, the mixture was refluxed at $130^{\circ} \mathrm{C}$ for $6 \mathrm{~h}$, it was allowed to cool for $6 \mathrm{~h}$ after stopping $\mathrm{N}_{2}$ to achieve separation, the solvent substance was vacuumed. The solid produce was washed in deionized water to separate and extract, and for additional purification the substance was next moved through a silica column with DMF and dried under vacuum at $120^{\circ} \mathrm{C}$ [51]. $2 \mathrm{~g} \mathrm{Fe}_{3} \mathrm{O}_{4}$ /APTES nanoparticles with $0.247 \mathrm{~g}$ (DCHC) and $20 \mathrm{~mL}$ DMF were mixed under $\mathrm{N}_{2}$ atmosphere; $0.458 \mathrm{~g} \mathrm{Ga}$ (TCPP) mixed in $5 \mathrm{~mL}$ DMF were added and were refluxed under $\mathrm{N}_{2}$ atmosphere at $140^{\circ} \mathrm{C}$ for $8 \mathrm{~h}$. A high flow of $\mathrm{N}_{2}$ was used to prevent decomposition of DMF during the reaction. The product was washed with DMF, DCM and methanol after reaction, until porphyrin with an electrostatic bond mixed with $\mathrm{Fe}_{3} \mathrm{O}_{4}$ /APTES exited quickly and the product remained at $80^{\circ} \mathrm{C}$ for $24 \mathrm{~h}$, to be dried and extra solvent could be exhausted. DCHC was used as a catalyst for making the bond between $\mathrm{COOH}$ groups and $\mathrm{NH}_{2}$ groups on the magnetite surface (Figure 2).

Sorption procedure: Batch-sorption were performed by mixing 10 $\mathrm{mL}$ Fluoride aqueous solution $\left(10.0 \mathrm{mg} \mathrm{L}^{-1}\right)$ and various amounts (10-100 mg) dry powder of the $\mathrm{Fe}_{3} \mathrm{O}_{4} / \mathrm{APTES} / \mathrm{Ga}$ (TCPP) nanoparticles in using a sonication method for $30 \mathrm{~min}$. then, the 
sorbent was separated before measurement, the Fluoride removal efficiency was calculated according to Equation (1) in the text:

Fluoride removal efficiency $(\%)=\left(\mathrm{C}_{0}-\mathrm{C}_{\mathrm{f}}\right) / \mathrm{C}_{0} \times 100(1)$

where $\mathrm{C}_{0}$ and $\mathrm{C}_{\mathrm{f}}$ are the initial and final concentration of the fluoride ion, before and after the sorption, respectively.

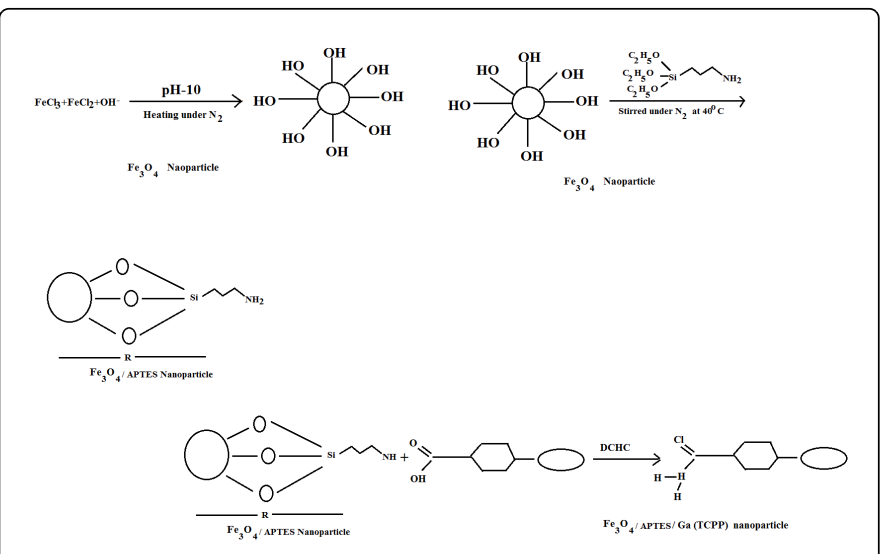

Figure 2: Chemical functionalization magnetite surface using APTES followed by metalloporphyrin insertion. (APTES=3aminopropyltriethoxysilane and DCHC=dicyclohexylcarbodiimide and TCPP=tetrakis (4-carboxyphenl) porphyrin).

\section{Results and Discussion}

\section{Characterization of nanomagnets}

XRD spectrum: Structure and particle size were determined by $\mathrm{XRD}$, the crystalline structure of synthesized nanoparticles is shown in the XRD analysis. The Joint Committee on Powder Diffraction Standards (JCPDS) reference pattern of magnetite (No.19-629) is included for comparison. The XRD spectrum shows diffractions and the fact that $\mathrm{Fe}_{3} \mathrm{O}_{4}$ is available in the spinel phase. Existing peaks in (220), (311), (400), (511) and (411) indicate cubic spinel phases of $\mathrm{Fe}_{3} \mathrm{O}_{4} \cdot \mathrm{Fe}_{3} \mathrm{O}_{4}$, is completely pure due to lack of any peaks in 20-30 For $\mathrm{y}-\mathrm{Fe}_{2} \mathrm{O}_{3}$ [52], observation of peaks in the first section indicates synthesized magnetite; the second section shows modification of the magnetite surface and the third section is related to functionalization of the magnetite. All of the peaks in three parts are similar, indicating the stability of the crystalline phase of the nanoparticles. The results of the XRD analysis from the synthesized substance indicate the diameter of particles to be equal to $45 \mathrm{~nm}$ in histogram.
FT-IR spectrum: This method was employed for determining functional groups this is represented in Table 1. This Table displays all of the parts for three curve (a), (b), (c). Curve (a) relates to $\mathrm{Fe}_{3} \mathrm{O}_{4}$ and curve (b) associates to $\mathrm{Fe}_{3} \mathrm{O}_{4}$ /APTES and curve (c) links to $\mathrm{Fe}_{3} \mathrm{O}_{4}$ l $\mathrm{APTES} / \mathrm{Ga}$ (TCPP) (Figure 3).

\begin{tabular}{|l|l|}
\hline Functional Groups & Wavenumber $\left(\mathbf{c m}^{-1}\right)$ \\
\hline Fe-O & $580 \mathrm{~cm}^{-1}$ \\
\hline Si-O-Si & $1115 \mathrm{~cm}^{-1}$ \\
\hline Si-OH & $1030 \mathrm{~cm}^{-1}$ \\
\hline N-H stretching vibration & $1640 \mathrm{~cm}^{-1}$ and $3445 \mathrm{~cm}^{-1}$ \\
\hline C=H stretching vibration & $2862 \mathrm{~cm}^{-1}$ and $2930 \mathrm{~cm}^{-1}$ \\
\hline O=C-N amide group & $1687 \mathrm{~cm}^{-1}$ \\
\hline C=C stretching vibration & $1500 \mathrm{~cm}^{-1}$ \\
\hline
\end{tabular}

Table 1: Indicating Functional Groups with Wavenumber $\left(\mathrm{cm}^{-1}\right)$.

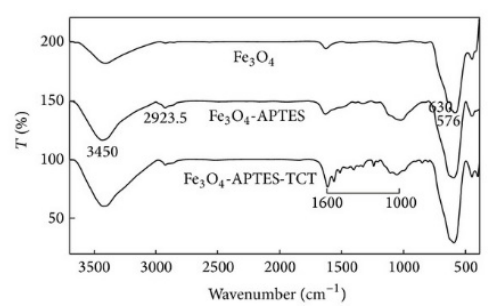

Figure 3: FTIR spectra of $\mathrm{Fe}_{3} \mathrm{O}_{4}$ nanoparticles (a), $\mathrm{Fe}_{3} \mathrm{O}_{4}$ /APTES nanoparticles (b), $\mathrm{Fe}_{3} \mathrm{O}_{4} / \mathrm{APTES} / \mathrm{Ga}$ (TCPP) nanoadsorbents (c).

Thermogravimetric Analysis (TGA): Consider (Table 2), in this study to identify the number of modifiers quantitatively, a TGA thermogram was used. This thermogram was illustrated in weight loss Curve (a) relates to $\mathrm{Fe}_{3} \mathrm{O}_{4}$, curve (b) associates to $\mathrm{Fe}_{3} \mathrm{O}_{4}$ /APTES and curve (c) links to $\mathrm{Fe}_{3} \mathrm{O}_{4} / \mathrm{APTES} / \mathrm{Ga}$ (TCPP) [46]. These data show that $\mathrm{Fe}_{3} \mathrm{O}_{4}$ /APTES nanoparticles have been modified with metalloporphyrin successfully using a chemical bond. Two important advantages for this experiment were observed. The first advantage was the formation of a chemical bond of metalloporphyrin ligand on the $\mathrm{Fe}_{3} \mathrm{O}_{4}$ /APTES nanoparticles, which was physical sorption; the second advantage was the use of an external magnetic field for regenerating the nanosorbant [53-55] this is illustrated in Figure 4.

\begin{tabular}{|c|c|c|}
\hline $\mathrm{Fe}_{3} \mathrm{O}_{4}$ & \multicolumn{2}{|c|}{ Stages } \\
\hline a) $\mathrm{Fe}_{3} \mathrm{O}_{4}$ & Weight loss of $1 \%$ & Oxidation $\mathrm{Fe}_{3} \mathrm{O}_{4}$ to $\mathrm{Fe}_{2} \mathrm{O}_{3}$ \\
\hline \multirow[t]{2}{*}{ b) $\mathrm{Fe}_{3} \mathrm{O}_{4} / \mathrm{APTES}$} & The first weight loss stage was $2 \%$ & Decomposition of APTES \\
\hline & The second weight loss stage was $7 \%$ & Gathering silanol group $(\mathrm{OH})$ \\
\hline \multirow[t]{2}{*}{ C) $\mathrm{Fe}_{3} \mathrm{O}_{4} / \mathrm{APTES} / \mathrm{Ga}$ (TCPP) } & The first weight loss stage was $4 \%$ & Missing magnetite humidity \\
\hline & The second weight loss stage was $6 \%$ & Decreasing the APTES layer \\
\hline
\end{tabular}


Citation: Asgari B, Bowen J (2017) Gallium (III)-Metalloporphyrin Grafted Magnetite Nanoparticles for Fluoride Removal from Aqueous Solutions.

Table 2: a) $\mathrm{Fe}_{3} \mathrm{O}_{4}$ with one stage of weight loss, b) $\mathrm{Fe}_{3} \mathrm{O}_{4}$ /APTES with two stages of weight loss, c) $\mathrm{Fe}_{3} \mathrm{O}_{4} / \mathrm{APTES} / \mathrm{Ga}$ (TCPP) with three stages of weight loss.

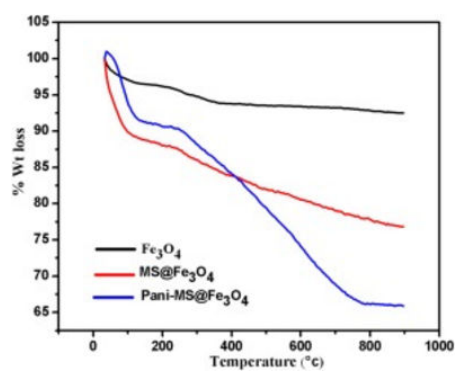

Figure 4: Thermogravimetric analysis of $\mathrm{Fe}_{3} \mathrm{O}_{4}$ nanoparticles (a), $\mathrm{Fe}_{3} \mathrm{O}_{4}$ /APTES nanoparticles (b), $\mathrm{Fe}_{3} \mathrm{O}_{4} /$ APTES/Ga (TCPP) nanoadsorbents (c).

TEM analysis: As shown in Figure 5(a) The black powder is $\mathrm{Fe}_{3} \mathrm{O}_{4}$ that is completely clear and pure due to lack of any peaks in 20-30 For $\gamma-\mathrm{Fe}_{2} \mathrm{O}_{3}$ [8] in XRD pattern and Figure 5(b) shows the APTES causes the some of the black powders $\mathrm{Fe}_{3} \mathrm{O}_{4}$ gather together and Figure 5(c) depicts the core of dark magnetic nanoparticles is coated with a gray shell. It is shown that magnetic nanoparticles are covered by $\mathrm{Ga}(\mathrm{TCPP})$; the magnetic nanoparticles have a spherical shape and the majority of particles are in the size range 40-50 $\mathrm{nm}$.
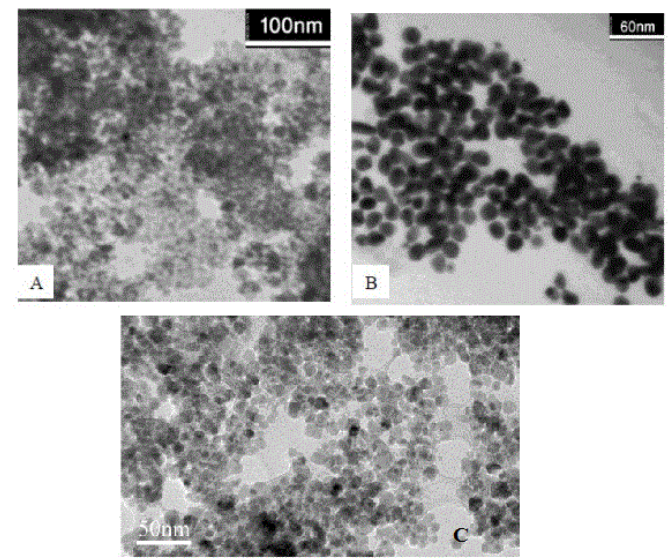

Figure 5: TEM images of $\mathrm{Fe}_{3} \mathrm{O}_{4}$ (1), $\mathrm{Fe}_{3} \mathrm{O}_{4}$ /APTES (2), $\mathrm{Fe}_{3} \mathrm{O}_{4} /$ APTES/Ga(TCPP) (3).

\section{Optimization of the parameters}

Effect of solution $\mathrm{pH}$ : Power of Hydrogen $(\mathrm{pH})$ is one of the most important factors in substance adsorption in that suitable $\mathrm{pH}$ can raise yield sorption. In this study, $\mathrm{pH}$ values in the range between 3-11 were considered to measure the $\mathrm{pH}$. Based on results, the highest fluoride removal percentage with $\mathrm{Fe}_{3} \mathrm{O}_{4}$ /APTES/Ga (TCPP) nanosorbent in 95\%-96\% was seen at $\mathrm{pH}$ values in the range between 5-7. At lower $\mathrm{pH}$ values the fluoride removal decreased, since the metalloporphyrin complex experienced only minor dementalization during contact with the low $\mathrm{pH}$ solution and at higher $\mathrm{pH}$ values the fluoride removal also decreased due to the existence of competition between the hydroxyl groups and fluoride ions on active sites of the sorbent $[37,42,56,57]$ are presented in Figure 6.

Effect of the adsorbent dosage: It was seen that by raising the amount of adsorbent, fluoride removal was increased, reaching a steady value for $50 \mathrm{mg}$ adsorbent dosage. Using various amounts (10-100 mg) of $\mathrm{Fe}_{3} \mathrm{O}_{4}$ /APTES/Ga (TCPP) nanosorbents in fluoride removal achieved $96 \%$. Thus, for all the experiments in this study, the adsorbent dosage was $50 \mathrm{mg}[58,59]$ (Figure 7).

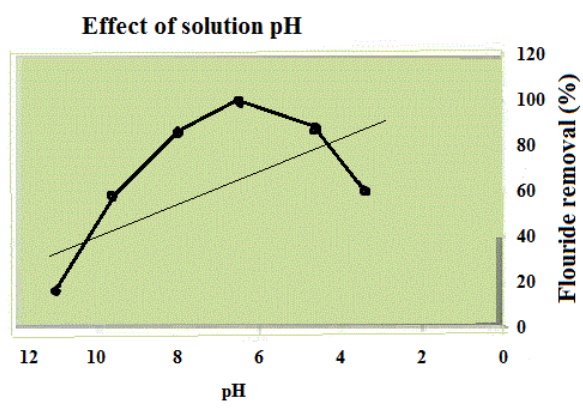

Figure 6: The $\mathrm{pH}$ influence on the removal efficiency of fluoride (amount of adsorbents: $50 \mathrm{mg}$; fluoride concentration: $10 \mathrm{mg}$. $\mathrm{L}^{-1}$ ).

Effect of the contact time: The time of fluoride removal was considered for the $\mathrm{Fe}_{3} \mathrm{O}_{4} / \mathrm{APTES} / \mathrm{Ga}$ (TCPP) nanosorbent in $0-60$ minutes, which determined the effect of the contact time on the fluoride removal with nanosorbent. It was seen that fluoride removal from the $\mathrm{Fe}_{3} \mathrm{O}_{4}$ /APTES/Ga (TCPP) nanosorbents was rapid at $30 \mathrm{~min}$, so there was not a higher percent in the removal of fluoride are presented in Figure 8, in contact time $30 \mathrm{~min}$ fluoride removal achieved $93 \%$.

Removal of fluoride from spiked sample: The solution of fluoride with $10 \mathrm{mg} / \mathrm{L}$ concentration was spiked with deionized water. The adsorption experiment was done on $10 \mathrm{~mL}$ of this spiked sample under optimal condition (contact time, 30 min, $\mathrm{pH}$ 5.5, and $\mathrm{Fe}_{3} \mathrm{O}_{4} /$ APTES/Ga (TCPP) nanosorbent $50 \mathrm{mg}$ ). It was seen that fluoride content decreased from $10.0 \mathrm{mg} / \mathrm{L}$ to $0.3 \mathrm{mg} / \mathrm{L}(97.0 \pm 0.7 \%)$. 


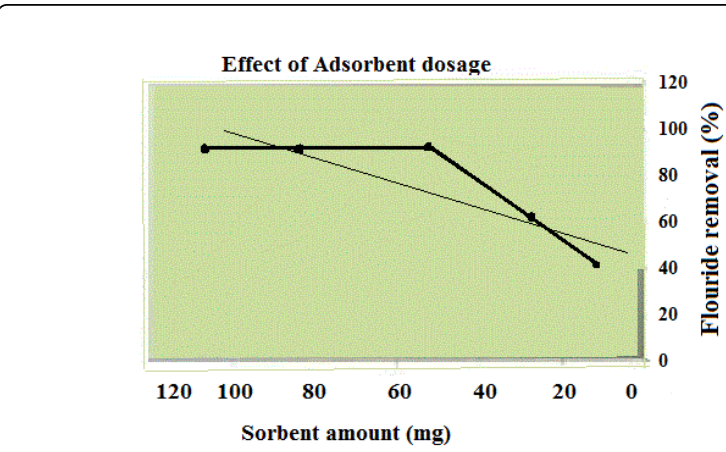

Figure 7: Effect of nanoadsorbent dosage on the on-fluoride removal (fluoride concentration: $10 \mathrm{mg} \mathrm{L}^{-1}, \mathrm{pH}$ of the solution: 5.5 , contact time: $30 \mathrm{~min})$.

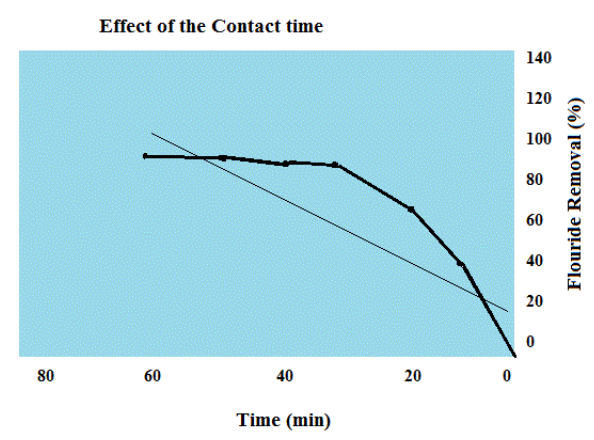

Figure 8: Effect of contact time on the adsorption of fluoride by modified nanoparticles ( $\mathrm{pH}$ of the solution=5.5; amount of adsorbent $=50 \mathrm{mg}$; fluoride concentration $=10 \mathrm{mg}$. $\mathrm{L}^{-1}$ ).

Effect of co-existing anions: Wastewater has many ions with different concentration which depends on their source. The presence of these ions may have an effect on the extraction efficiency of $\mathrm{Fe}_{3} \mathrm{O}_{4} /$ APTES/Ga (TCPP) nanosorbents because of competition for binding with active sites between fluoride ions and foreign ions. The presence of other ions may interfere in the indicated fluoride adsorption; for this reason, the effect of foreign ions in fluoride removal has been studied. Some of the co-existing anion $\mathrm{SO}_{4}{ }^{2-}, \mathrm{NO}_{3}{ }^{-}, \mathrm{NO}_{2}{ }^{-}, \mathrm{Cl}^{-}$were investigated (the concentration of every anion was $10 \mathrm{mg} / \mathrm{L}$ ) Because the tolerance range was defined at $\pm 5 \%$, and the presence of anions had no notable effect on the fluoride removal efficiency in solution, it is possible for Ga (III) porphyrin complexes to form selective bonds with fluoride [60].

Regeneration of the used sorbent: Regeneration is very important in the development of an economic process. In this study, $\mathrm{NaOH}$ solution was selected for regeneration $\mathrm{Fe}_{3} \mathrm{O}_{4}$ /APTES/Ga (TCPP) nanosorbent from fluoride ions. The concentration obtained by using $\mathrm{NaOH} 10.0$ $\mathrm{mM}$ solution after optimizing was $98 \%$, indicated the highest recovery of fluoride ions from the adsorbents (Figure 9).

Removal of fluoride from real sample: A sample was selected from wastewater released by the glass industry (Kaveh glass industry group, Saveh, Iran) as can be seen from Table 3. A comparison was performed between fluoride removal efficiency of the proposed nanosorbent with the commercially available activated alumina (KHD-12 from Sumitomo Chemical Co Ltd, Japan). The results show the untreated wastewater had fluoride concentration of $35.5 \pm 1.2 \mathrm{mg} / \mathrm{L}$. It has been found that the proposed nanosorbent efficiently removes fluoride from wastewater and decreases the fluoride concentration to $2.8 \pm 0.03 \mathrm{mg} / \mathrm{L}$ which was fairly the same as the commercial one $(2.5 \pm 0.08 \mathrm{mg} / \mathrm{L})$, showing that the proposed nanosorbent can be exploited for defluoridation in real field condition.

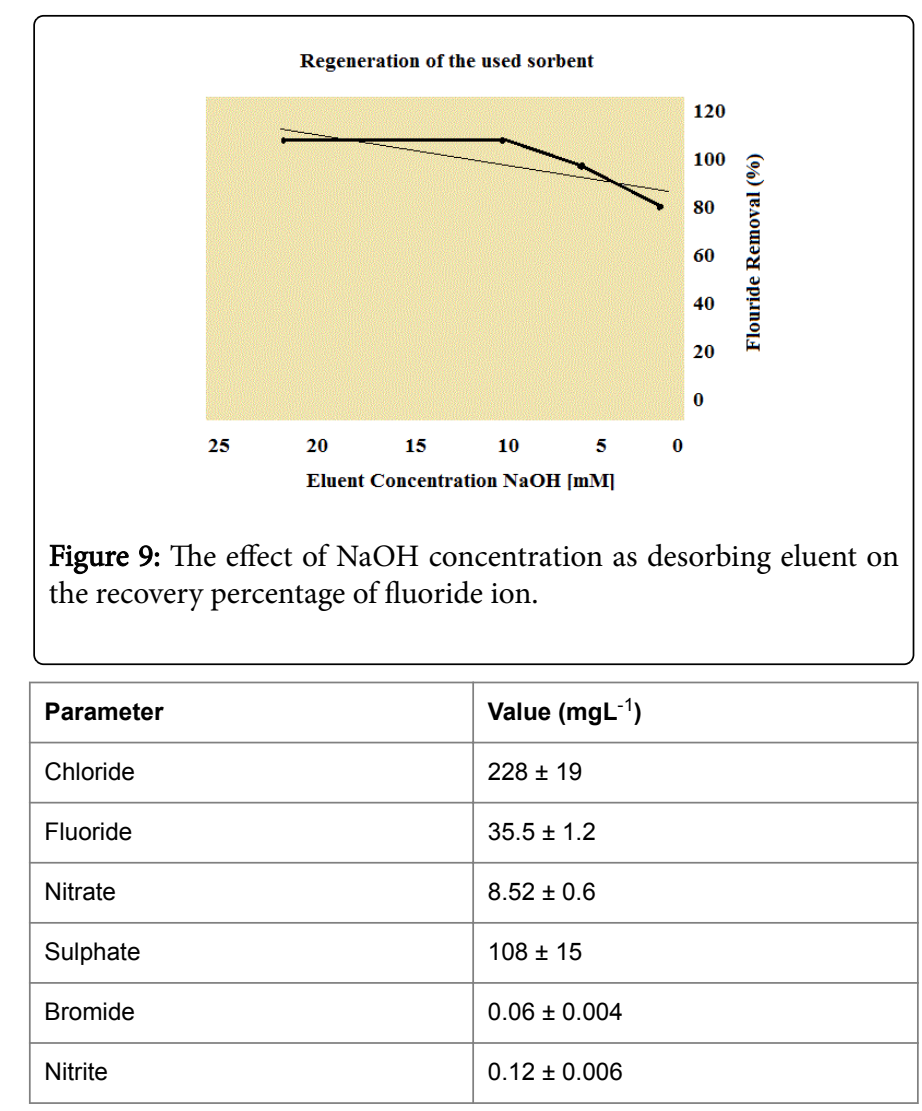

Table 3: The characteristics of glass industrial wastewater used in this study.

Reusability of the recycled sorbent: Regeneration and recovery can be considered important factors for evaluating the effect of efficiency. After the first regeneration, this process was continued for five cycles. In this study, the fluoride removal efficiency of the $\mathrm{Fe}_{3} \mathrm{O}_{4} / \mathrm{APTES} / \mathrm{Ga}$ (TCPP) nanoadsorbents from five cycles were 97.2\%, 96.8\%, 95.5\%, $94.3 \%$, and $87.0 \%$ respectively. It was observed that modified nanoparticles can regenerate and be used more than once, providing an economic advantage for this experiment.

\section{Conclusion}

This technique has been done in controlling the concentration of fluoride in water problems at mining operation that it effects on the environment that it is one of the remarkable targets mine water and the environment. Fluoride pollution of the industrial wastewaters is one of the significant problems worldwide imposing a serious threat to human health. Magnetite nanoparticles were modified by grafting $\mathrm{Ga}$ (TCPP) groups at the surface of $\mathrm{Fe}_{3} \mathrm{O}_{4}$ /APTES, and their ability to extract fluoride ions from aqueous solutions was evaluated. This study indicates that magnetite nanoparticles show good efficiency in removing fluoride ions and they can be selective for target anions. The results also indicate that magnetite nanoparticles can be used 
interchangeably as magnetic Ionics, with the ability to separate fluoride ions from other liquid solution. The $\mathrm{pH}$ efficiency and presence of other ions were also investigated for removal efficiency. Two main advantages of the nanomaterial produced are ease of removal from the magnetic field and the possibility for easy regeneration after washing the fluoride ion with alkaline solution. Regeneration of the fluoride Ion and the feasibility for reuse are other advantages of this method.

\section{Acknowledgement}

The authors thank the Research Institute of Petroleum Industry for their help with this study.

\section{References}

1. Zhang T, Li Q, Liu Y, Duan Y, Zhang W (2011) Equilibrium and kinetic studies of fluoride ions adsorption on $\mathrm{CeO} 2 / \mathrm{Al} 2 \mathrm{O} 3$ composite pretreated with non-thermal plasma. Chem Eng J 168: 665-671.

2. Kamga ET, Alonzo V, Nijiki CP, Audebrand N, Ngameni E, et al. (2010) Preparation and characterization of charcoals that contain dispersed $\mathrm{Al} 2 \mathrm{O} 3$ as adsorbent for removal of fluoride from drinking water. water Treat 48: 333-343.

3. Turner BD, Binning P, Stipp SLS (2005) Fluoride removal by calcide: evidence for fluoride precipitation and surface adsorption. Environ Sci Technol 30: 9561-9568.

4. Islam M, Mishra PC, Patel R (2011) Fluoride adsorption from aqueous solution by hybrid thorium phosphate composite. Chem Eng J 166: 978-985.

5. Samatya S, Mijuki H, Ito Y, Kawakita H, Uezu K (2010) The effect of polystyrene as a progen on the fluoride ion sorption of $\mathrm{Zr} 4+-$ surface immobilized resin. React Funct Polym 70: 63-68.

6. Sujana MG, Thakur SB, Rao SB (1998) Removal of fluoride from aqueous solution by using alum sludge. J Collo Interf Sci 206: 94-101.

7. Wolkersdorfer $\mathrm{CH}$ (2005) Mine water tracer as a basis for remediation. Chemie der Erde 65: 65-74.

8. Yamaura M, Camilo RL, Sampaio LC, Macêdo MA, Nakamura M (2004) Preparation and characterization of (3-aminopropyl) triethoxysilanecoated magnetite nanoparticles. J Magnet Magn Mat 279: 210-217.

9. Joshi SV, Mehta SH, Rao AP, Rao AV (1992) Estimation of sodium fluoride using HPLC in reverse osmosis experiments. Water Treatm 7: 207-210.

10. Tahaikt M, El Habbani R, Ait Haddou A, Achary I, Amor Z, et al. (2007) Fluoride removal from groundwater by nanofiltration. Desalin 212: 46-53.

11. Adhikary SK, Tipnis UK, Harkare WP, Govindan KP (1989) Defluoridation during desalination of brackish water by electrodialysis. Desalin 71: 301-312.

12. Hichour M, Persin F, Sandeaux J, Gavach C (1999) Fluoride removal from waters by Donnan dialysis. Separa and Purific Technol 18: 1-11.

13. Karthikeyan G, Sundar Raj AS, Meenakshi S, Elango KP (2004) Adsorption dynamics and the effect of temperature of fluoride at alumina-solution interface. J Indian Chem Soc 81: 461-466.

14. Meenakshi S, Viswanathan N (2007) Identification of selective ionexchange resin for fluoride sorption. J Coll Interf Sci 308: 438-450.

15. Bhargava DS, Killedar DJ (1992) Fluoride adsorption on fishbone charcoal through a moving media adsorber. Water Res 26: 781-788.

16. Venkata Mohan S, Ramanaiah SV, Rajkumar B, Sarma PN (2007) Biosorption of fluoride from aqueous phase onto algal Spirogyra IO1 and evaluation of adsorption kinetics. Biores Technol 98: 1006-1011.

17. Bühlmann P, Pretsch E, Bakker E (1998) Carrier-based ionselective electrodes and bulk optodes 2-Ionophores for Potentiometric and Optical Sensors. Chem Rev 98: 1593-1688.
18. Park SB (1992) Mechanistic and Analytical Studies of MetalloporphyrinBased Anion- Selective Electrodes. The University of Michigan, Ann Arbor.

19. Valiotti AB, Shumilova GI, Druzina ZE (1997) Anion-selective electrodes based on gallium tetraphenylporphine. Russian J Gen Chem 67: 495-498.

20. Li P, Miser DE, Rabiei S, Yadav RT, Hajaligol MR (2003) The removal of carbon monoxide by iron oxide nanoparticles. Applied Catalysis B: Environ 43: 151-162.

21. Mak SY, Chen DH (2004) Fast adsorption of methylene blue on polyacrylic acid-bound iron oxide magnetic nanoparticles. Dyes Pigme 61: 93-98.

22. Uheida A, Salazar-Alvarez G, Björkman E, Yu Z, Muhammed M (2006) $\mathrm{Fe} 3 \mathrm{O} 4$ and $\gamma$ - $\mathrm{Fe} 2 \mathrm{O} 3$ nanoparticles for the adsorption of $\mathrm{Co} 2+$ from aqueous solution. J Colloid Interf Sci 298: 501-507.

23. Mayo JT, Yavuz C, Yean S, Cong L, Shipley H, et al. (2007) The effect of nanocrystalline magnetite size on arsenic removal. Sci Technol Adv Mat 8: 71-75.

24. Blaney LM, Cinar S, SenGupta AK (2007) Hybrid anion exchanger for trace phosphate removal from water and wastewater. Water Res 41: 1603-1613.

25. Hristovski K, Westerhoff P, Möller T, Sylvester P, Condit W (2008) Simultaneous removal of perchlorate and arsenate by ion-exchange media modified with nanostructured iron (hydr)oxide. J Hazard Mat 152: 397-406.

26. Teunissen W, Bol AA, Geus JW (1999) Magnetic catalyst bodies. Cataly Today 48: 329-336.

27. Yoon TJ, Lee W, Oh YS, Lee JK (2003) Magnetic nanoparticles as a catalyst vehicle for simple and easy recycling. New J Chem 27: 227-229.

28. Stevens PD, Li G, Fan J, Yen M, Gao Y (2005) Recycling of homogeneous Pd catalysts using superparamagnetic nanoparticles as novel soluble supports for Suzuki, Heck, and Sonogashira cross-coupling reactions. Chem Communica, pp: 4435-4437.

29. Lee D, Lee J, Lee H, Jin S, Hyeon T (2006) Filtration-free recyclable catalytic asymmetric dihydroxylation using a ligand immobilized on magnetic mesocellular mesoporous silica. Adv Synth and Cataly 348: 41-46.

30. Ó Dálaigh C, Corr SA, Gun'ko Y, Connon SJ (2007) A magneticnanoparticle-supported 4-N, N-dialkylaminopyridine catalyst: Excellent reactivity combined with facile catalyst recovery and recyclability. Angewandte Chemie 119: 4407-4410.

31. Yoon H, Ko S, Jang J (2007) Nitrogen-doped magnetic carbon nanoparticles as catalyst supports for efficient recovery and recycling. Chem Commun, pp: 1468-1470.

32. Zhang Y, Li Z, Sun W, Xia C (2008) A magnetically recyclable heterogeneous catalyst: Cobalt nanooxide supported on hydroxyapatiteencapsulated $\gamma$-Fe2O3 nanocrystallites for highly efficient olefin oxidation with $\mathrm{H} 2 \mathrm{O} 2$. Cataly Communica 10: 237-242.

33. Seiler K, Simon W (1992) Theoretical aspects of bulk optode membranes. Analytica Chimica Acta 266: 73-87.

34. Gupta VK, Jain AK, Singh LP, Khurana U (1997) Porphyrins as carrier in PVC based membrane potentiometric sensors for nickel(II). Analytica Chimica Acta 355: 33-41.

35. Legin AV, Rudnitskaya AM, Vlasov YG, Di Natale C, D’Amico A (1999) The features of the electronic tongue in comparison with the characteristics of the discrete ion-selective sensors. Sensors and Actuators B: Chem 58: 464-468.

36. Sadeghi S, Shamsipur M (2000) Lead(II)-selective membrane electrode based on tetraphenylporphyrin. Analy Lett 33: 17-28.

37. Steinle ED, Amemiya S, Bühlmann P, Meyerhoff ME (2000) Origin of Non-Nernstian anion response slopes of metalloporphyrin-based liquid/ polymer membrane electrodes. Analy Chem 72: 5766-5773.

38. Biesaga M, Pyrzyńska K, Trojanowicz M (2000) Porphyrins in analytical chemistry-A review. Talanta 51: 209-224.

39. Malinowska E, Niedziółka J, Meyerhoff ME (2001) Potentiometric and spectroscopic characterization of anion selective electrodes based on 
Citation: Asgari B, Bowen J (2017) Gallium (III)-Metalloporphyrin Grafted Magnetite Nanoparticles for Fluoride Removal from Aqueous Solutions.

metal(III) porphyrin ionophores in polyurethane membranes. Analytica Chimica Acta 432: 67-78.

40. Gupta VK, Kumar A, Mangla R (2001) Protoporphyrin IX dimethyl ester as active material in PVC matrix membranes for the fabrication of zinc(II) selective sensor. Sensors and Actuators B: Chem 76: 617-623.

41. Zhang W, Rozniecka E, Malinowska E, Parzuchowski P, Meyerhoff ME (2002) Optical chloride sensor based on dimer-monomer equilibrium of indium(III) octaethylporphyrin in polymeric film. Analy Chem 74: 4548-4557.

42. Malinowska E, Górski E, Meyerhoff ME (2002) Zirconium(IV)porphyrins as novel ionophores for fluoride-selective polymeric membrane electrodes. Analytica Chimica Acta 468: 133-141.

43. Górski $€$, Malinowska E (2005) Fluoride-selective of sensors based on the polyurethane membranes doped with $\mathrm{Zr}(\mathrm{IV})$-porphyrins. Analytica Chimica Acta 540: 159-165.

44. Iwado A, Mifune M, Hazawa T, Mukuno T, Oda J (1999) Peroxidase-like activity of ion exchange resins modified with metalporphine in fluorescent flow injection analysis. Analy Sci 15: 841-846.

45. Mifune M, Sugimoto K, Iwado A, Akizawa H, Motohashi N, et al. (2003) Flow injection analysis of hydrogen peroxide using glass-beads modified with manganese(III)-tetra(4-carboxyphenyl) porphine derivative and its analytical application to the determination of serum glucose. Analy Sci 19: 569-573.

46. Poursaberi T, Hassanisadi M, Torkestani M, Zare M (2012) Development of Zirconium (IV) metalloporphyrin grafted $\mathrm{Fe} 3 \mathrm{O} 4$ nanoparticles for efficient fluoride removal. Chem Eng J 189-190: 117-125.

47. Maity D, Agrawal DC (2007) Synthesis of iron oxide nanoparticles under oxidizing environment and their stabilization in aqueous and nonaqueous media. J Magne Magnet Mat 308: 46-55.

48. Ozmen M, Can K, Arslan G, Tor A, Cengeloglu Y, et al. (2010) Adsorption of $\mathrm{Cu}$ (II) from aqueous solution by using modified $\mathrm{Fe} 3 \mathrm{O} 4$ magnetic nanoparticles. Desalin 254: 162-169.

49. Sayin S, Ozcan F, Yilmaz M (2010) Synthesis and evaluation of chromate and arsenate anions extraction ability of a $\mathrm{N}$-methylglucamine derivative of calix [4] arene immobilized onto magnetic nanoparticles. J Hazard Mat 178: 312-319.
50. Sun L, Zhang C, Chen L, Liu J, Jin H, et al. (2009) Preparation of aluminacoated magnetite nanoparticle for extraction of trimethoprim from environmental water samples based on mixed hemimicelles solid-phase extraction. Analytica Chimica Acta 638: 162-168.

51. Changfu Z, Xuexin T, Dong W, Aiqing X, Wenhui L (2009) An unsymmetrical porphyrin and its metal complexes: Synthesis, spectroscopy, thermal analysis and liquid crystal properties. J Serbian Chem Soc 74: 1097-1104.

52. Porra RJ, Ross BD (1964) Haem synthase and cobalt porphyrin synthase in various micro-organisms. Biochem J 94: 557-562.

53. Cai JH, Huang JW, Zhao P, Ye YJ, Yu HC (2009) Silica metalloporphyrins hybrid materials: preparation and catalysis to hydroxylate cyclohexane with molecular oxygen. J Sol-Gel Sci Technol 50: 430-436.

54. Espinosa M, Terres E, Pacheco S, Mejia R, Rodriguez R (2010) Sol-gel synthesis and characterization of SBA-15 in presence of metalloporphyrins: m-5,10,15,20 TPP-Ni2+, Etio-III-Ni2+ and Etio-IIIVO2+. J Sol-Gel Sci Technol 53: 239-245.

55. Kosal ME, Suslick KS (2000) Microporous porphyrin and metalloporphyrin materials. J Solid State Chem 152: 87-98.

56. Mitchell-Koch JT, Pietrzak M, Malinowska E, Meyerhoff ME (2006) Aluminum(III) porphyrins as ionophores for fluoride selective polymeric membrane electrodes. Electroanal 18: 551-557.

57. Kang Y, Lutz C, Hong SA, Sung D, Lee JS, et al. (2010) Development of a fluoride-selective electrode based on scandium(III) octaethylporphyrin in a plasticized polymeric membrane. Bulletin of the Korean Chem Soc 31: 1601-1608.

58. Biswas K, Gupta K, Goswami A, Ghosh UC (2010) Fluoride removal efficiency from aqueous solution by synthetic iron(III)-aluminum(III)chromium(III) ternary mixed oxide. Desalin 255: 44-51.

59. Van Caneghem J, Block C, Vandecasteele C (2010) Assessment of the impact on human health of industrial emissions to air: Does the result depend on the applied method. J Hazard Mat 184: 788-797.

60. Pimenta AM, Araújo AN, Montenegro MCBSM, Pasquini C, Rohwedder JJR, et al. (2004) Chloride-selective membrane electrodes and optodes based on an indium(III) porphyrin for the determination of chloride in a sequential injection analysis system. J Pharmac Biomed Analy 36: 49-55. 